\title{
Trends in the use of oral contraceptives among adolescents and young women in Spain
}

\author{
Pilar Carrasco-Garrido ${ }^{1 *}$, Ana López de Andrés ${ }^{1}$, Valentín Hernández-Barrera ${ }^{1}$, Isabel Jiménez-Trujillo', \\ Mercedes Esteban-Peña ${ }^{2}$, Napoleón Pérez-Farinós ${ }^{3}$ and Rodrigo Jiménez-García ${ }^{1}$
}

\begin{abstract}
Background: We aimed to determine the prevalence of consumption of oral contraceptives (OCs) among adolescents and young women living in Spain and to identify the factors associated with this consumption.

Methods: We performed a cross-sectional study on the consumption of OCs by women aged 15-30 years residing in Spain. We used secondary individualized data from the $2006(n=2513)$ and $2012(n=1530)$ Spanish National Health Surveys. The dependent variable was the use of OCs in the previous 2 weeks. Independent variables included sociodemographic characteristics, comorbidity, lifestyle, and healthcare resource utilization.

The prevalence of OC consumption was analysed by investigating the changes observed between 2006 and 2012. We used multivariate logistic regression to identify the independent factors associated with OC use in each year.

Results: In 2006, $14.42 \%$ of women reported using OCs; this percentage dropped to $10.21 \%$ in $2012(p<0$. 05). Multivariate analysis revealed an association between $O C$ use and visits to the gynaecologist (AOR, 5.60 [95 \% Cl, 2.93-10.73] in 2006; and AOR, 3.55 [95 \% Cl, 1.30-9.73] in 2012), Pap smear tests (AOR, 1.8 [95 \% $\mathrm{Cl}, 1.23-2.87]$ in 2006; and AOR, 2.42 [95 \% Cl, 1.30-4.51] in 2012), and smoking in 2006 (AOR, 1.42 [95 \% $\mathrm{Cl}, 1.04-1.93])$.

Conclusions: There was a significant decrease in OC use from 2006 to 2012 among adolescents and young women living in Spain. In the present study, consumers of OCs were women who visited a gynaecologist more often and complied more with preventive measures such as Pap smear testing. Also, women who reported having used OCs were more likely to smoke than the rest of the study population, although the smoking habit is a risk factor for thrombotic events in women who take OCs.
\end{abstract}

\section{Plain english summary}

The introduction of the oral contraceptive pill has allowed women to exercise greater control over the childbearing phase of their life. The objectives of the present study are to describe, using the data drawn from the 2006 and 2012 Spanish National Health Surveys (SNHS), the prevalence of contraceptive methods and identify factors associated with the use of contraception

\footnotetext{
* Correspondence: pilar.carrasco@urjc.es

${ }^{1}$ Preventive Medicine and Public Health Teaching and Research Unit, Health Sciences Faculty, Rey Juan Carlos University, Avda. Atenas s/n.

28922-Alcorcón, Madrid, Spain

Full list of author information is available at the end of the article
}

by adolescents and young women resident in Spain. Our study population comprised women aged 15 to 30 . A total of 4043 women were included: 2513 from the 2006 SNHS and 1530 from the 2012 SNHS. The interviews were conducted between June 2006 and June 2007 (SNHS2006); and from July 2011 to June 2012 (SNHS2012). The surveys use multistage cluster sampling, with proportional random selection of primary and secondary sampling units (towns and sections, respectively), and the final units (individuals) are selected by means of random routes and sex- and age-based quotas. 
This study found a significant decrease in OC use among adolescents and young women living in Spain from 2006 to 2012. The decrease in consumption of OCs in Spain has two possible explanations: first, the decrease could be due to a change in the social perception of oral contraceptives in Spain in terms of family planning policy, because the male condom is the first choice, and second, the economic recession seems to have affected some indicators of sexual and reproductive health. The OC consumers in our study were women who visited a gynaecologist more often and complied more with preventive measures such as Pap smear testing. Also, women who reported having used OCs were more likely to smoke than the rest of the study population, although the smoking habit is a risk factor for thrombotic events in women who take OCs.

\section{Article summary Strengths}

- The strengths of our study include its large population-based sample size, a randomly selected population, the use of a standardized survey, training of the data collectors, and our ability to control for a broad range of major covariates.

\section{Limitation}

- We used data from a cross-sectional survey, we cannot determine cause and effect relationships between the variables associated with OC use.

- The SNHSs, rather than identifying specific active pharmaceutical ingredients, identify groups of medicines for specific diseases or disorders. Consequently, we do not know whether OCs are COCs or whether they are progestin-only pills (POPs, the Mini-Pill).

\section{Background}

Modern contraception is one of the great public health achievements of the last century. The introduction of the oral contraceptive (OC) pill has allowed women to exercise greater control over the childbearing phase of their life. Several studies show that OCs are the most popular form of reversible contraception in developed countries [1-4]. However, many teenage pregnancies are unplanned and generate a significant societal cost and potential individual risk [5]. Around the world, approximately 16 million girls aged 15 to 19 and some one million girls under 15 give birth every year, and $85 \%$ of these pregnancies are unplanned [6]. Every year in Spain, there are about 4000 term pregnancies in adolescents under the age of 17 [7]. Investigations carried out on the use of contraception among Spanish women show that the male condom is the most common method, followed by OCs $[8,9]$. OCs in Spain are available with prescription or as over-the-counter (OTC) products. Oral contraceptives are available to Spanish women age 15 and older at pharmacies, and there is no age limit on the availability of emergency contraception. Contraceptives are reasonably priced and are partially subsidized. The price has not changed in recent years.

These findings are reflected in the Sexual Attitude of Females in Europe Survey, which reveals significant differences between the low use of pills in Spain and the high demand in other countries (Italy, UK, France, Germany, Sweden, Denmark, Norway, the Czech Republic, Austria, Estonia, Latvia, Lithuania, and the Russian Federation) [5, 10]. The Health Behaviour in SchoolAged Children Study 2009/2010 showed that, among 15-year-old Spanish adolescents, $8 \%$ of girls and $3 \%$ of the respondents' male partners reported using contraceptive pills during their last intercourse [11]. However, forthcoming social and legislative changes in the area of sexual and reproductive health in Spain could have an impact on the patterns of use of contraception among adolescents and young women. An example of a policy change, that has already been implemented, is the OTC availability of the emergency contraception in Spanish pharmacies since 2010.

In this context, we aimed to determine the prevalence of OC consumption among adolescents and young women living in Spain and to identify the factors associated with this consumption. We also analysed how this prevalence changed from 2006 to 2012.

\section{Methods}

We conducted a nationwide, descriptive, cross-sectional epidemiological study on the consumption of OCs by adolescents and young women aged $15-30$ years residing in Spain. We used individualized secondary data from the 2006 and 2012 Spanish National Health Surveys (SNHS) $[12,13]$. SNHSs are interview-based surveys conducted by the Ministry of Health in collaboration with the National Statistics Institute (Instituto Nacional de Estadística) that target a large sample of the non-institutionalized Spanish population. The surveys use multistage cluster sampling, with proportional random selection of primary and secondary sampling units (towns and sections, respectively). The final units (individuals) are selected by means of random routes and sex- and age-based quotas. The 2006 survey included 29,478 adults of both sexes interviewed between June 2006 and June 2007; the 2012 survey included 20,007 persons interviewed from July 2011 to June 2012. Details of SNHS methodology are described elsewhere $[12,13]$. The variables included in our study were created on the basis of a series of identically worded questions asked in the two surveys used. Information 
was collected by direct home-based computer-assisted interviews. The persons interviewed responded to the questionnaires. Surveyors were previously trained in basic communication skills, related procedures and specific training on the questionnaire to be used.

Our study population comprised women aged 15 to 30. A total of 4043 women were included: 2513 from the 2006 SNHS and 1530 from the 2012 SNHS.

The information to create the dependent variables was obtained from the answers "yes" or "no" to the question "In the last two weeks have you taken the contraceptive pill?". Respondents who answered "yes" were then asked the question "Were they prescribed for you by a doctor?" Those who answered yes to the first question, regardless of the answer to the second one, were considered consumers of OCs.

The independent variables were the primary sociodemographic characteristics of the population, namely, age, nationality, marital status, occupational status, educational level, total household monthly income in euros, and social class. The categories for these variables are shown in Table 1.

Self-rated health was analysed as a dichotomous variable (very good/good vs. fair/poor/very poor).

Variables related to comorbid chronic illness were also analysed. These were collected using the question "Has the doctor told you that you suffer from one of these diseases?" The list of diseases comprised arterial

Table 1 Sociodemographic characteristic of the study population. Spanish National Health Surveys 2006 and 2012

\begin{tabular}{llll}
\hline & & SNHS 2006 & SNHS 2012 \\
& & N (\%) & N (\%) \\
\hline Age & $15-22$ & $827(32.91)$ & $612(40)$ \\
Nationality & $23-30$ & $1686(67.09)$ & $918(60)$ \\
& Immigrants & $394(15.68)$ & $205(13.40)$ \\
Marital status & Spanish & $2119(84.32)$ & $1325(86.60)$ \\
& Not married & $1821(72.46)$ & $1278(83.58)$ \\
Occupational status & Married & $692(27.54)$ & $251(16.42)$ \\
& Employed & $1355(53.92)$ & $605(39.54)$ \\
& Unemployed & $313(12.46)$ & $264(17.25)$ \\
Educational level & Inactive & $845(33.63)$ & $661(43.20)$ \\
& Junior school & $382(15.56)$ & $669(43.72)$ \\
& High school & $1523(62.04)$ & $567(37.06)$ \\
& University and & $550(22.4)$ & $294(19.22)$ \\
& higher education & & \\
Monthly income & $\leq 1200$ euros & $842(33.77)$ & $536(35.61)$ \\
& $>1200$ euros & $1651(66.23)$ & $969(64.39)$ \\
Social class & High & $317(16.52)$ & $249(16.93)$ \\
& Middle & $667(34.76)$ & $472(32.09)$ \\
& Low & $935(48.72)$ & $750(50.99)$ \\
\hline
\end{tabular}

hypertension, hypercholesterolemia, heart disease, and diabetes. Women who reported suffering from one or more of these conditions were classified as "chronic sufferers". The presence of depression or anxiety (psychological disorders) was assessed using the following questions: 1) "Have you suffered from depression or anxiety in the last 12 months?" And for those who answered "yes" 2) "Has your doctor confirmed the diagnosis?" Only women who answered "yes" to both questions were considered to have a psychological disorder.

The lifestyle-related variables used in the study were as follows: currently smoking (yes/no), consumption of alcoholic beverages in the 2 weeks prior to the survey (yes/no), leisure time physical activity (intense or moderate vs. none), and self-reported body mass index (calculated from self-reported height and weight) categorized as $<25,25-30$ and $>30$.

In order to assess the use of healthcare resources, subjects were asked about the following: i) visits to their general practitioner in the last 12 months, ii) type of health insurance (public vs. private), iii) visits to the gynaecologist in the last 12 months, iv) Pap smear test in the last 12 months, v) use of family planning services, vi) consumption of any type of medication in the last two weeks, and vii) use of any alternative medicine in the last two weeks.

\section{Statistical analysis}

We calculated the prevalence of total consumption of OCs for each of the two surveys and according to the study variables. For the bivariate comparison of proportions, Pearson's $\chi 2$ or Fisher's exact test was applied, with values of $p<0.05$ taken as significant. To estimate the independent effect of $\mathrm{OC}$ use on study variables, we also obtained the corresponding adjusted odds ratio (AOR) through multivariate logistic regression analysis. All variables that showed a significant association $(p<$ 0.05 ) in the bivariate analysis were included in the multivariate analysis, along with variables that were considered relevant in the scientific literature.

Finally, to assess the time trend in the consumption of OCs during the study period, we combined the respective databases of the two SNHS and calculated the crude and adjusted odds ratios for having consumed OCs in 2012 compared with 2006. To calculate the AOR, all variables that proved to be predictive in either SNHS were included in the multivariate logistic regression.

Estimates were made using the svy (survey commands) functions of the Stata program (STATA Corp, College Station, Texas, USA), which enabled us to incorporate the sampling design and weights into all of the statistical calculations (descriptive, $X^{2}$, logistic regression). Statistical significance was established as a two-tailed $\alpha<0.05$. 


\section{Results}

The study was based on data from 4043 women (2513 from the 2006 SNHS and 1530 from the 2012 SNHS) aged 15-30 residing in Spain who answered the question on consumption of OCs in the two weeks immediately preceding the survey. Descriptions of the sociodemographic characteristics of the study population are shown in Table 1.

The 2006 SNHS data revealed that $14.42 \%$ (95 \% CI, 12.75-16.27) of adolescents and young women residing in Spain reported having taken the contraceptive pill in the two weeks leading up to the survey. This proportion decreased to $10.21 \%$ (95 \% CI, 8.61-12.07) in 2012, and the crude difference proved statistically significant association $(p<0.05)$. Consumption was almost entirely by prescription, with the percentages of self-medication being only $5.90 \%$ (95 \% CI, 3.26-10.44) in 2006 and $4.84 \%$ (95\% CI, 2.44-9.35) in 2012.

Table 2 shows data on the prevalence of consumption of OCs according to the sociodemographic characteristics of the population and lifestyle variables. The bivariate analysis revealed that the prevalence of OC use was highest in women aged 23 to 30 years during the study period (17.375 in 2006 and $13.32 \%$ in 2012), $p<0.05$. It is noteworthy that the frequency of $\mathrm{OC}$ consumption was higher for university-educated women, women with higher incomes, and smokers, a finding that was repeated to a significant degree in both surveys $(p<0.05)$. Identical results were obtained for alcohol consumption.

Table 3 shows the consumption of OCs as reported by study participants and according to comorbid conditions and use of healthcare resources. In 2006, OC consumption

Table 2 Prevalence of oral contraceptive use in adolescents and young women living in Spain, according to socio-demographic variables and lifestyle. Spanish National Health Surveys 2006 and 2012

\begin{tabular}{|c|c|c|c|}
\hline & & \multicolumn{2}{|l|}{ Oral contraceptive use } \\
\hline & & SNHS $2006 \%(95 \%$ Cl) & SNHS $2012 \%(95 \%$ Cl) \\
\hline \multirow[t]{2}{*}{$\mathrm{Age}^{*}+$} & $15-22$ & $9.71(7.47-12.52)$ & $5.93(4.33-8.07)$ \\
\hline & $23-30$ & $17.37(15.12-19.87)$ & $13.32(10.91-16.17)$ \\
\hline \multirow[t]{2}{*}{ Nationality } & Immigrants & $14.63(10.58-19.87)$ & $8.96(5.21-14.96)$ \\
\hline & Spanish & $14.37(12.60-16.35)$ & $10.52(8.83-12.47)$ \\
\hline \multirow[t]{2}{*}{ Marital status } & Not married & 13.77 (11.90-15.89) & $9.87(8.24-11.79)$ \\
\hline & Married & $16.61(13.19-20.71)$ & $12.03(7.52-18.71)$ \\
\hline \multirow[t]{3}{*}{ Occupational status* ${ }^{*}$} & Employed & $18.45(15.84-21.37)$ & $13.28(10.53-16.62)$ \\
\hline & Unemployed & $11.91(8.37-16.67)$ & $9.22(6.16-13.58)$ \\
\hline & Inactive & $9.70(7.53-12.42)$ & $8.08(5.91-10.94)$ \\
\hline \multirow[t]{3}{*}{ Educational level*† } & Junior school & 11.00 (7.75-15.38) & $7.69(5.55-10.57)$ \\
\hline & High school & 14.09 (12.00-16.47) & $10.83(8.41-13.82)$ \\
\hline & University and higher education & $18.16(14.35-22.72)$ & 15.08 (10.93-20.44) \\
\hline \multirow[t]{2}{*}{ Monthly incomet } & $\leq 1200$ euros & $12.89(10.09-16.34)$ & $7.75(5.64-10.57)$ \\
\hline & $>1200$ euros & $15.36(13.32-17.66)$ & $11.34(9.25-13.83)$ \\
\hline \multirow[t]{3}{*}{ Social Class } & High & $19.14(13.82-25.67)$ & $11.40(7.76-16.45)$ \\
\hline & Middle & $15.72(12.29-18.77)$ & $11.70(8.90-15.23)$ \\
\hline & Low & $14.03(11.11-17.45)$ & $8.87(6.74-11.57)$ \\
\hline \multirow[t]{2}{*}{ Smoking habit*十 } & Non smoker & $12.04(10.21-14.15)$ & $8.98(7.19-11.15)$ \\
\hline & Smoker & $19.11(15.89-22.81)$ & $13.24(10.15-17.11)$ \\
\hline \multirow[t]{2}{*}{ Alcohol consumption* } & No & $11.38(8.86-14.49)$ & $9.90(8.12-12.03)$ \\
\hline & Yes & $15.92(13.82-18.28)$ & $11.37(8.14-15.68)$ \\
\hline \multirow[t]{2}{*}{ Physical activity } & Moderate & $15.33(13.08-17.89)$ & $11.10(8.90-13.76)$ \\
\hline & inactive & $13.30(10.92-16.11)$ & $9.87(7.56-12.80)$ \\
\hline \multirow[t]{3}{*}{ Body Mass Index Kg/sq.m } & $<25$ & $14.19(12.28-16.35)$ & $11.31(9.35-13.63)$ \\
\hline & $25-29$ & $16.91(12.72-22.14)$ & $6.52(3.96-10.58)$ \\
\hline & 30 or over & $16.30(9.02-27.65)$ & $9.18(4.15-19.11)$ \\
\hline Total consumption of OCs & & $14.42(12.75-16.27)$ & $10.21(8.61-12.07)$ \\
\hline
\end{tabular}

*Statistically significant association of consumption in SNHS $2006(p<0.05)$

tStatistically significant association of consumption in SNHS $2012(p<0.05)$ 
Table 3 Prevalence of oral contraceptive use in adolescents and young women living in Spain, according to comorbidity and use of healthcare resources. Spanish National Health Surveys 2006 and 2012

\begin{tabular}{|c|c|c|c|}
\hline & & \multicolumn{2}{|l|}{ Oral contraceptive use } \\
\hline & & SNHS $2006 \%$ (95 \% Cl) & SNHS $2012 \%$ (95\% Cl) \\
\hline \multirow[t]{2}{*}{ Self-assessment of health status } & Very good / Good & $13.75(11.91-15.82)$ & $10.14(8.45-12.12)$ \\
\hline & Fair / Poor / Very poor & $17.30(13.58-21.78)$ & $10.81(6.65-17.10)$ \\
\hline \multirow[t]{2}{*}{ Chronic illness* } & No & $13.56(11.77-15.46)$ & $9.76(8.08-11.74)$ \\
\hline & Yes & $19.78(14.96-25.68)$ & $13.47(9.02-19.63)$ \\
\hline \multirow[t]{2}{*}{ Psychological disorders* } & No & $14.03(12.31-15.96)$ & $10.04(8.40-11.97)$ \\
\hline & Yes & $19.16(13.33-26.76)$ & $13.25(7.45-22.46)$ \\
\hline \multirow[t]{2}{*}{ Medical consultation* } & No & $12.40(10.59-14.47)$ & $9.75(7.86-12.05)$ \\
\hline & Yes & $18.48(15.20-22.29)$ & $11.25(8.52-14.70)$ \\
\hline \multirow[t]{2}{*}{ Type of health insurance coverage } & Private & $14.78(8.39-24.72)$ & $14.12(9.71-20.08)$ \\
\hline & Public & $14.41(12.69-16.31)$ & $9.61(7.94-11.60)$ \\
\hline \multirow[t]{2}{*}{ Gynecologist visits in preceding 12 months* +} & No & $2.27(1.37-3.74)$ & $1.95(0.9-4.17)$ \\
\hline & Yes & $20.09(17.76-22.64)$ & $13.86(11.66-16.40)$ \\
\hline \multirow[t]{2}{*}{ Pap smear in preceding 12 months* ${ }^{*}$} & No & $7.19(5.43-9.48)$ & $3.69(2.38-5.68)$ \\
\hline & Yes & $22.48(19.74-25.49)$ & $15.96(13.32-19.00)$ \\
\hline \multirow[t]{2}{*}{ Family planning services in preceding 12 months* } & No & $12.85(11.25-14.64)$ & $9.81(8.23-11.67)$ \\
\hline & Yes & $41.78(31.12-53.27)$ & $19.39(10.05-34.11)$ \\
\hline \multirow[t]{2}{*}{ Medication consumption*十 } & No & $14.24(12.49-16.18)$ & $9.46(7.90-11.28)$ \\
\hline & Yes & $16.46(11.30-23.35)$ & $19.93(12.01-31.23)$ \\
\hline \multirow[t]{2}{*}{ Alternative medicines* $†$} & No & $14.11(12.42-15.99)$ & $9.66(8.07-11.53)$ \\
\hline & Yes & $23.09(14.32-35.02)$ & $28.39(16.44-44.40)$ \\
\hline
\end{tabular}

*Statistically significant association of consumption in SNHS $2006(p<0.05)$

†Statistically significant association of consumption in SNHS $2012(p<0.05)$

was greater among adolescents and young women with psychological disorders $(19.16 \%, p<0.05)$. Both surveys also showed that consumption was more common among those who had made at least one visit to a gynecologist in the past year than among those who had not. In addition, the Pap smear test was more prevalent among women using the pill (28.42\% vs. $7.19 \%$ in 2006 and $15.96 \%$ vs. $3.69 \%$ in 2012) $p<0.05$ and women using family planning services.

The multivariate logistic regression analysis showed the effect of each of the study variables, duly adjusted for the remainder, on the overall consumption of OCs in the study sample. These estimates were made for both surveys and are shown in Table 4.

In 2006, the variables that were independently and significantly associated with a higher likelihood of OC use were smoking (AOR 1.42; 95\%CI 1.04-1.93), $p=$ 0.020 , visits to the gynaecologist in the preceding 12 months (AOR, 5.6; $95 \% \mathrm{CI}, 2.93-10.73$ ), $p=0.000$, having a Pap smear test (AOR 1.85; 95\%CI, 1.23-2.87), $p=0.003$, and visiting family planning services (AOR, 3.56; $95 \%$ CI, 2.14-5.93), $p=0.000$.

In 2012, some of the predictive variables were the same as in 2006, such as visits to the gynaecologist (AOR 3.55;
$95 \%$ CI, 1.30-9.73), $p=0.022$, Pap smear tests (AOR 2.42; $95 \%$ CI 1.30-4.51), $p=0.004$, although a new variable, use of alternative medicines (AOR, 2.83; $95 \% \mathrm{CI}$, 1.32-6.04), $p=0.008$, was also assessed.

The adjusted OR for having consumed OCs in 2012 with respect to 2006 was 0.67 (95\% CI, 0.52-0.85), $p=0000$. Therefore, after controlling for possible confounders, the likelihood of having consumed OCs in 2012 was lower than it had been 6 years previously.

\section{Discussion}

National health surveys have become a valid and widely used research tool for ascertaining patterns of OC use in the female population [14-17]. According to data from a recent report with updated information on the sexual behaviour of adolescents and the use of contraception, the hormonal contraceptive method most commonly used by adolescents is the combined oral contraceptive (COC) (55.6\% of young women have used an OC) [18]. Recent studies on the development of OCs over time show that this method has become increasingly common among Spanish women [15, 19, 20]. Use of hormonal contraception is mainly among women aged 20 to $30[5,9]$. 
Table 4 Factors associated with consumption of oral contraceptives in adolescents and young women living in Spain. Spanish National Health Surveys 2006-2012

\begin{tabular}{|c|c|c|c|c|c|c|c|}
\hline \multirow[t]{2}{*}{ Variables } & & \multicolumn{3}{|l|}{ SNHS 2006} & \multicolumn{3}{|l|}{ SNHS 2012} \\
\hline & & Adjusted OR & $95 \% \mathrm{Cl}$ & $p$-value & Adjusted OR & $95 \% \mathrm{Cl}$ & $p$-value \\
\hline \multirow[t]{2}{*}{ Age } & $15-22$ & 1 & & & 1 & & \\
\hline & $23-30$ & 0.92 & $(0.61-1.36)$ & 0.867 & 1.29 & $(0.80-2.05)$ & 0.257 \\
\hline \multirow[t]{2}{*}{ Smoking habit } & Non smoker & 1 & & & 1 & & \\
\hline & Smoker & 1.42 & $(1.04-1.93)$ & 0.020 & NS & & 0.547 \\
\hline \multirow[t]{2}{*}{ Gynecologist visits in preceding 12 month } & No & 1 & & & 1 & & \\
\hline & Yes & 5.60 & $(2.93-10.73)$ & 0.000 & 3.55 & $(1.30-9.73)$ & 0.022 \\
\hline \multirow[t]{2}{*}{ Pap smear test in preceding 12 months } & No & 1 & & & 1 & & \\
\hline & Yes & 1.87 & $(1.23-2.87)$ & 0.003 & 2.42 & $(1.30-4.51)$ & 0.004 \\
\hline \multirow[t]{2}{*}{ Family planning services in preceding 12 months } & No & 1 & & & 1 & & \\
\hline & Yes & 3.56 & $(2.14-5.93)$ & 0.000 & NS & & 0.147 \\
\hline \multirow[t]{2}{*}{ Alternative medicines } & No & 1 & & & 1 & & \\
\hline & Yes & NS & & 0.851 & 2.83 & $(1.32-6.04)$ & 0.008 \\
\hline
\end{tabular}

Data are expressed as adjusted odds ratio (AOR) and $95 \%$ confidence intervals $(95 \% \mathrm{Cl}$ )

NS non-significant association

However, the present study revealed a significant decrease in the consumption of OCs during the study period 2006-2012 (AOR, 0.67; $95 \%$ CI, 0.52-0.85), which is consistent with the results of a recent study by Zelić-Kerep et al. [21], who quantified and analysed trends in the use of oral hormonal contraceptives in the city of Zagreb, Croatia. Their results showed a $76 \%$ decrease in the use of hormonal contraceptives from 2008 to 2009.

In the 2012, the prevalence of OC use reached $10.21 \%$ among adolescents and young women living in Spain. This percentage was considerably lower than the $16.2 \%$ found by Cea-Soriano et al. [22] in a study to determine prescription contraceptive use in the United Kingdom with data from The Health Improvement Network (THIN). Løkkegaard [23] also showed higher percentages of OC use among Danish female adolescents. By age 17, more than $50 \%$ of Danish female adolescents had had a prescription for hormonal contraceptives. Similarly, a recent study showed that, among Portuguese adolescents, $33 \%$ of girls and $18 \%$ of the respondents' male partners had used contraceptive pills during their most recent intercourse [11].

The decrease in consumption of OCs in Spain has two possible explanations. First, different investigations conducted in Spain on the use of contraceptive methods among the female Spanish population indicate that condoms are the method most used in our country. The rate of condom use in Spain is relatively high (71\%) in adolescents and young adults [8] in comparison with other European countries, such as Greece (53.87 \%) [24] and Sweden (68\%) [25]. Many investigations highlight the fact that the use of condoms in the Spanish population has not decreased; on the contrary, it continues to increase in percentage terms (38.8 \% in 2007 to $46.7 \%$ in 2012). Second, the economic recession seems to have affected some indicators of sexual and reproductive health. Since the beginning of the recession, contraceptive use has declined [26], and access to contraception has become difficult because of cost [27]. In this sense, if our National Health system continues to stop funding new-generation OCs, which are more efficient and safer, new barriers to their distribution would appear [28]. Therefore, young Spanish women would choose other contraceptive methods. In addition, since 2010, the emergency contraception has been sold directly in Spanish pharmacies without the need for a medical prescription. It is possible that when women were provided EC without a prescription, they were more likely to use the method [29, 30].

The association between copayment and hormonal contraception was analysed by Kazerooni et al. [31] and Poncet et al. [32], whose results show the relationship between socioeconomic status and the use and method of contraception among women residents in France.

OCs remain an effective form of contraception, despite the availability of newer methods such as intrauterine devices or the extended-cycle pill. Generic and OTC contraceptives are favored by third-party payers. As a result, potentially exciting developments in the safety of branded oral contraceptives may have gone unnoticed [33]. However, Foster et al. [34], showed that the interest in OTC access to oral contraceptives is high. If out-ofpocket costs for such pills are low, OTC access could have a significant effect on the use of effective contraceptives and unintended pregnancy. In this sense, cost will continue to determine whether these new contraceptive methods are accepted, unless substantial health benefits 
can be adequately proven. The economic recession may have played a role in this decrease.

A lifestyle analysis revealed that, in 2006, women who reported having used OCs were more likely to smoke than the rest of the study population (AOR, 1.42; $95 \%$ CI, 1.04-1.93). Several studies have reported that OCs and smoking-derived nicotine are known to synergistically increase the risk and severity of cerebral ischemia in women [35]. COC users who are current smokers have a tenfold higher risk of myocardial infarction and an almost threefold risk of stroke than those who do not [36]. The study by Berlín et al. in France [37] showed that hormonal contraception in adolescent girls can accelerate the metabolism of cotinine. The increased rates of smoking among teenagers are not unique of Spain. Adolescents start smoking in response to social influences, emulating the behavior of friends and family members, and are influenced by the media. There is a possible relation between smoking and early sexual initiation. Recent studies show that the smoking prevalence is higher among disadvantaged groups [38], and also that girls with low educational and socioeconomic status tend to experience sex at a younger age. This situation is a window of opportunity to promote hormonal contraception [39]. Interventions targeting young women should be developed to increase their knowledge about contraceptive methods and the risk of smoking.

As for preventive measures, our results show that during the study period, OC users were more likely to have a Pap smear test than women who did not use OCs. We must also bear in mind that the International Agency for Research on Cancer (IARC) has classified COCs as carcinogenic for humans. Therefore, regular smear tests in sexually active women can be considered the best method for the prevention of cervical cancer.

As for healthcare resource-related variables, our results revealed that the variable with the greatest strength of association with $\mathrm{OC}$ use in both surveys was visits to the gynaecologist in the previous 12 months (AOR, 5.60 [95 \% CI, 2.93-10.73] in 2006 and AOR, 3.55 [95 \% CI, 1.30-9.73] in 2012). Adolescents are a special group who need motivational counselling and care to ensure that they adhere to the daily routine and to continue regular use $[40,41]$. As a result, gynaecologists attempt to adapt prescriptions to the specific characteristics of available pills in order to improve adherence [42]. A working knowledge of contraception will assist the paediatrician and gynaecologist in both promoting sexual health and treating common adolescent gynaecological problems.

Family planning services were also associated with OC use. In 2006, young women who reported having used OCs were more likely to visit family planning services than women who did not (AOR, 3.56 [95 \% CI, 2.14-5.93]). These results are consistent with those of other studies on the utilization and perception of health services, such as the REPROSTAT project (Reproductive health indicators in the European Union), which highlighted that only $31 \%$ of the youths interviewed had ever visited a health center to receive information on contraception, pregnancy, abortion, and STIs [43]. In the same line Darney et al. [44] in a study conducted in Mexico, to determine associations between age and patient-reported quality of family planning services among adolescents and young women, showed that although a lower proportion of adolescents reported long-acting reversible contraception (LARC) use, in comparison with young women, the adolescents using hormonal and LARC had significantly lower odds of reporting high-quality care compared with women aged 25-29. The role of family planning services is essential because the evidence supports that teenagers are more likely to choose a LARC method and continue with that method if they are offered [45].

Finally, in the 2012 SNHS, women who reported having used OCs were more likely to use alternative medicines than the rest of the study population (AOR, 2.83 [95 \% CI, 1.32-6.04]). It is known that interactions between hormonal contraceptives and other herb-drugs can reduce the efficacy of OCs [46]. In the USA, Murphy et al. [47] evaluated the effect of the herbal remedy St. John's Wort on OCs and found that treatment with St. John's Wort was associated with a significant 13-15\% reduction in exposure to the OC.

The strengths of our study include its large populationbased sample size, a randomly selected population, the use of a standardized survey, training of the data collectors, and our ability to control for a broad range of major covariates, including sociodemographic factors and variables associated with the use of health services. However, our study is also subject to a number of possible limitations. First, since we used data from a cross-sectional survey, we cannot determine cause and effect relationships between the variables associated with $\mathrm{OC}$ use. Second, the conclusions drawn are difficult to generalize, because the survey has not been validated for the consumption of medication. Third, information obtained from interviews is subjective and may be subject to recall errors or the tendency of subjects to give socially desirable responses. Another possible limitation of SNHSs is that, rather than identifying specific active pharmaceutical ingredients, they identify groups of medicines for specific diseases or disorders. Consequently, we do not know whether OCs are COCs or whether they are progestin-only pills (POPs, the Mini-Pill). Furthermore, the SNHS does not allow us to differentiate between women who took emergency contraceptives and women who had taken any kind of $\mathrm{OC}$ or other method used beside OCs. In the same line, the SNHS does not include data regarding LARCs use, among 
the population consulted, but other studies have found that the use of LARC is very low in Spain [48] compared with other countries, for example Mexico [44].

Finally, the SNHS does not include data about the sexual behaviour or reproductive and contraceptive knowledge of the population consulted. Finally, another limitation is that younger women who still live at their parents' house because the they have not completed high school/university and/or have not started working full time, are affected by factors such as economic status and parental education.

Lastly, given that the initial response rate to the 2006 SNHS was $65 \%$ and the initial response rate to the 2012 SNHS was $61 \%$, a possible non-response bias must be considered $[12,13]$. According to the National Statistics Institute (INE), the initial non-response rate in both surveys was slightly higher among female, non-Spanish subjects, and those in the 40-65 age groups $[49,50]$.

\section{Conclusion}

We observed a significant decrease in OC use among adolescents and young women living in Spain from 2006 to 2012.

In the present study, consumers of OCs were women who visited their gynaecologist often and followed preventive measures such as Pap smear testing. Also, women who reported having used OCs were more likely to smoke than the rest of the study population, although the smoking habit is a risk factor for thrombotic events in women who take OCs.

\section{Acknowledgments}

We wish to thank the Ministry Health of Spain for data cession.

\section{Funding}

This study was funded by the FIS (Fondo de Investigaciones

Sanitarias-Health Research Fund, grant no. PI13/00369, Instituto de Salud Carlos III) co-financed by the European Union through the Fondo Europeo de Desarrollo Regional (FEDER, "Una manera de hacer Europa"). The funders had no role in study design, data collection and analysis, decision to publish, or preparation of the manuscript.

\section{Availability of data and material}

The datasets generated during and/or analysed during the current study are available in the "Microdatos anonimizados" repository, http://

www.msssi.gob.es/estadisticas/microdatos.do

\section{Authors' contributions}

CGP and JGR originated and designed the study and coordinated the writing of the article. HBV contributed to the analysis of the data and to the drafting of the paper. LAA, PFN, EPM and JTI, contributed to the interpretation of the results and to the drafting of the paper. All authors had full access to all the data in the study and take responsibility for the integrity of the data and the accuracy of the data analysis. All authors have seen and approved the final version. CGP is the guarantor.

\section{Competing interests}

The authors declare that they have no competing interests.

\section{Ethics approval and consent to participate}

In accordance with Spanish legislation, there is no need for Ethics Committee approval, since the database was obtained from the Spanish Ministry of Health, Social Services and Equality webpage, where it is publicly available. The data was provided to us and therefore analyzed anonymously.

\section{Author details}

${ }^{1}$ Preventive Medicine and Public Health Teaching and Research Unit, Health Sciences Faculty, Rey Juan Carlos University, Avda. Atenas s/n.

28922-Alcorcón, Madrid, Spain. ${ }^{2}$ Training and Research Unit Health Madrid, City of Madrid, Spain, 28009 Madrid, Spain. ${ }^{3}$ Food Safety Agency, Ministry of Health, 28071 Madrid, Spain

Received: 2 March 2016 Accepted: 14 September 2016

Published online: 23 September 2016

\section{References}

1. Darroch JE. Trends in contraceptive use. Contraception. 2013;87(3):259-63.

2. Keyes KM, Cheslack-Postava K, Westhoff C, Heim CM, Haloossim M, Walsh K, Koenen K. Association of hormonal contraceptive use with reduced levels of depressive symptoms: a national study of sexually active women in the United States. Am J Epidemiol. 2013;178(9):1378-88.

3. Philipson S, Wakefield CE, Kasparian NA. Women's knowledge, beliefs, and information needs in relation to the risks and benefits associated with use of the oral contraceptive pill. J Womens Health (Larchmt). 2011;20(4):635-42.

4. Cibula D. Women's contraceptive practices and sexual behavior in Europe. Eur J Contracept Reprod Health Care. 2008;13(4):362-75.

5. Tsui AO, McDonald-Mosley R, Burke AE. Family planning and the burden of unintended pregnancies. Epidemiol Rev. 2010;32(1):152-74.

6. World Health Organization. Adolescent pregnancy. (available) http://www. who.int/mediacentre/factsheets/fs364/en/. (Acceded 3 July 2016).

7. Álvarez Nieto C, Pastor Moreno G, Linares Abad M, Serrano Martos J, Rodríguez OL. Motivations for adolescent pregnancy. Gac Sanit. 2012:26(6):497-503.

8. Dueñas JL, Lete I, Arbat A, Bermejo R, Coll C, Doval JL, Martínez-Salmeán J, Pérez-Campos E, Serrano I. Trends in contraception use in Spanish adolescents and young adults (15 to 24 years) between 2002 and 2008 Eur J Contracept Reprod Health Care. 2013;18(3):191-8.

9. Lete I, Pérez-Campos E. Differences in contraceptive use between Spanish female healthcare providers and Spanish women in the general population aged 23 to 49 years: the HABITS Study. Eur J Contracept Reprod Health Care. 2014;19(3):161-8

10. Sexual Attitude of Female in Europe. Survey 2006. Available from http://www.equipodaphne.es/archivos/encuestas/Datos\%20SAFESeptiembre\%2006.pdf. (Acceded 10 June 2014).

11. Currie C, Zanotti C, Morgan A, Currie D, de Looze M, et al., editors. Sexual behavior: experience of sexual intercourse. In: Health behaviour in schoolaged children (HBSC) study: international report from the 2009/2010 survey, No. 6. Copenhagen: WHO Regional Office for Europe, 2012:173-76 Available: http://www.euro.who.int/_data/assets/pdf_file/0003/163857/Socialdeterminants-of-health-and-well-being-among-young-people.pdf?ua=1 (Acceded 20 Oct 2014).

12. Ministerio de Sanidad y Consumo. Encuesta Nacional de Salud 2006. Available at http://www.msc.es/estadEstudios/estadisticas/encuestaNacional/ encuestaNac2006/metodENS2006.pdf (Acceded 2 July 2014).

13. Ministerio de Sanidad, Servicios Sociales e Igualdad (2013). Encuesta Nacional de Salud de España 2011-12. Available at: http://www.msc.es/ estadEstudios/estadisticas/encuestaNacional/encuesta2011.htm (Accessed 2 July 2014).

14. Duke JM, Sibbritt DW, Young AF. Is there an association between the use of oral contraception and depressive symptoms in young Australian women? Contraception. 2007;75(1):27-31.

15. Carrasco-Garrido P, López de Andrés A, Hernández Barrera V, Jiménez-Trujillo I, Santos-Sancho J, Jiménez-García R. Predictors of Contraceptive Methods among Adolescents and Young Women Residing in Spain. J Sex Med. 2011;8(9):2431-8.

16. Moreau C, Bouyer J, Bajos N, Rodríguez G, Trussell J. Frequency of discontinuation of contraceptive use: results from a French population-based cohort. Hum Reprod. 2009;24(6):1387-92. 
17. Grossman D, Grindlay K, Li R, Potter JE, Trussell J, Blanchard K. Interest in over-the-counter access to oral contraceptives among women in the United States. Contraception. 2013;88(4):544-52.

18. Ott MA, Sucato GS, Committee on Adolescence. Contraception for adolescents. Pediatrics. 2014;134(4):e1257-81.

19. Dueñas JL, Lete I, Bermejo R, Arbat A, Pérez-Campos E, Martínez-Salmeán J, Serrano I, Doval JL, Coll C. Trends in the use of contraceptive methods and voluntary interruption of pregnancy in the Spanish population during 1997-2007. Contraception. 2011;83(1):82-7.

20. Carrasco-Garrido P, Hernández Barrera V, Martin-Lopez R, López de Andrés A, Esteban Hernandez J, Jiménez-García R. Increased use of oral contraceptives in Spain: related factors and time trend, 2003-2006. J Sex Med. 2011:8(2):383-90.

21. Zelić-Kerep A, Stimac D, Ozić S, Zivković K, Zivković N. A study on utilization of oral contraceptives in the City of Zagreb (2008-2010). Coll Antropol. 2014;38(2):589-93

22. Cea-Soriano L, García Rodríguez LA, Machlitt A, Wallander MA. Use of prescription contraceptive methods in the UK general population: a primary care study. BJOG. 2014;121(1):53-60.

23. Løkkegaard E, Nielsen AK. Adolescent girls in Denmark use oral contraceptives at an increasingly young age, and with more pauses and shifts. Dan Med J. 2014;61(10):A4936.

24. Donadiki EM, Jimenez-Garcla R, Velonakis EG, Hernandez-Barrera V, Sourtzi P, Lopez de Andres A, Jimenez-Trujillo I, Pino CG, Carrasco-Garrido P. Factors related to contraceptive methods among female higher education students in Greece. J Pediatr Adolesc Gynecol. 2013;26(6):334-9.

25. Häggström-Nordin E, Borneskog C, Eriksson M, Tydén T. Sexual behaviour and contraceptive use among Swedish high school students in two cities: comparisons between genders, study programmes, and over time. Eur J Contracept Reprod Health Care. 2011;16(1):36-46.

26. Larrañaga I, Martín U, Bacigalupe A. Sexual and reproductive health and the economic crisis in Spain. SESPAS report 2014. Gac Sanit. 2014;28 Suppl 1:109-15.

27. Yogalingam K, Kelleher C, Bourke A, Boduszek D, McGee H, Morgan K Experiences of crisis pregnancy among Irish and non-Irish adults living in Ireland: findings from the Irish Contraception and Crisis Pregnancy Survey 2010 (ICCP-2010). Ir J Med Sci. 2013;182(4):633-8.

28. Barometer of Women's Access to Modern Contraceptive Choice in 16 EU Countries Available in http://www.ippfen.org/resources/barometerwomens-access-modern-contraceptive-choice-16-eu-countries-call-action [acceded 25 Nov 2015].

29. Nappi RE, Lobo Abascal P, Mansour D, Rabe T, Shojai R, Emergency Contraception Study Group. Use of and attitudes towards emergency contraception: a survey of women in five European countries. Eur J Contracept Reprod Health Care. 2014;19(2):93-101.

30. López-Amorós M, Schiaffino A, Moncada A, Pérez G. Factors associated with self-reported use of emergency contraception among the school population aged 14-18 years. Gac Sanit. 2010;24(5):404-9.

31. Kazerooni R, Vu K, Takizawa A, Broadhead C, Morreale AP. Association of copayment and socioeconomic status with hormonal contraceptive adherence in a female veteran population. Womens Health Issues. 2014;24(2):e237-41.

32. Poncet LC, Huang N, Rei W, Lin YC, Chen CY. Contraceptive use and method among immigrant women in France: relationship with socioeconomic status. Eur J Contracept Reprod Health Care. 2013;18(6):468-79.

33. Nelson AL. An update on new orally administered contraceptives for women. Expert Opin Pharmacother. 2015;29:1-14.

34. Foster DG, Biggs MA, Phillips KA, Grindlay K, Grossman D. Potential public sector cost-savings from over-the-counter access to oral contraceptives. Contraception. 2015;91(5):373-9.

35. Raval AP, Borges-Garcia R, Diaz F, Sick TJ, Bramlett H. Oral contraceptives and nicotine synergistically exacerbate cerebral ischemic injury in the female brain. Transl Stroke Res. 2013:4(4):402-12.

36. Kaminski P, Szpotanska-Sikorska M, Wielgos M. Cardiovascular risk and the use of oral contraceptives. Neuro Endocrinol Lett. 2013;34(7):587-9. Review.

37. Berlin I, Gasior MJ, Moolchan ET. Sex-based and hormonal contraception effects on the metabolism of nicotine among adolescent tobacco-dependent smokers. Nicotine Tob Res. 2007;9(4):493-8.

38. Hiscock R, Bauld L, Amos A, Fidler JA Munafò M. Socioeconomic status and smoking: a review. Ann N Y Acad Sci. 2012;1248:107-23.
39. Lara LA, Abdo CH. Age at Time of Initial Sexual Intercourse and Health of Adolescent Girls. J Pediatr Adolesc Gynecol. 2016:29(5):417-23.

40. Aubény E, Buhler M, Colau JC, Vicaut E, Zadikian M, Childs M. The Coraliance study: non-compliant behavior. Results after a 6-month follow-up of patients on oral contraceptives. Eur J Contracept Reprod Health Care. 2004;9(4):267-77.

41. Bitzer J. Oral contraceptives in adolescent women. Best Pract Res Clin Endocrinol Metab. 2013;27(1):77-89.

42. Moreau C, Bouyer J, Gilbert F, Group C, Bajos N. Social, demographic and situational characteristics associated with inconsistent use of oral contraceptives: evidence from France. Perspect Sex Reprod Health. 2006;38(4):190-6.

43. Fronteira I, Oliveira da Silva M, Unzeitig V, Karro H, Temmerman M. Sexual and reproductive health of adolescents in Belgium, the Czech Republic, Estonia and Portugal. Eur J Contracept Reprod Health Care. 2009;14:215-20.

44. Darney BG, Saavedra-Avendano B, Sosa-Rubi SG, Lozano R, Rodriguez MI. Comparison of family-planning service quality reported by adolescents and young adult women in Mexico. Int J Gynaecol Obstet. 2016;134(1):22-8.

45. Atkin K, Beal MW, Long-Middleton E, Roncari D. Long-acting reversible contraceptives for teenagers: primary care recommendations. Nurse Pract. 2015;40(3):38-46.

46. Izzo AA, Ernst E. Interactions between herbal medicines and prescribed drugs: an updated systematic review. Drugs. 2009;69(13):1777-98.

47. Murphy PA, Kern SE, Stanczyk FZ, Westhoff CL. Interaction of St. John's Wort with oral contraceptives: effects on the pharmacokinetics of norethindrone and ethinyl estradiol, ovarian activity and breakthrough bleeding. Contraception. 2005;71(6):402-8.

48. Haimovich S. Profile of long-acting reversible contraception users in Europe. Eur J Contracept Reprod Health Care. 2009;14(3):187-95.

49. Instituto Nacional de Estadística. Encuesta Nacional de Salud 2006 Evaluación de la falta de respuesta en la Encuesta Nacional de Salud 2006. Available in: http://www.ine.es/daco/daco42/sanitarias/evaluacion06.pdf (Acceded 4 July 2014).

50. Instituto Nacional de Estadística. Encuesta Nacional de Salud 2012. Evaluación de la falta de respuesta en la Encuesta Nacional de Salud 2011-2012. Available in: http://www.ine.es/daco/daco42/sanitarias/ evaluacion12.pdf (Acceded 4 July 2014).

\section{Submit your next manuscript to BioMed Central and we will help you at every step:}

- We accept pre-submission inquiries

- Our selector tool helps you to find the most relevant journal

- We provide round the clock customer support

- Convenient online submission

- Thorough peer review

- Inclusion in PubMed and all major indexing services

- Maximum visibility for your research

Submit your manuscript at www.biomedcentral.com/submit
) Biomed Central 